\title{
Investigating the Association Between Baseline Characteristics (HbA1c and Body Mass Index) and Clinical Outcomes of Fast-Acting Insulin Aspart in People with Diabetes: A Post Hoc Analysis
}

\author{
Keith Bowering (D) · Helena W. Rodbard · David Russell-Jones • \\ Bruce Bode - Stewart Harris - Milivoj Piletic - Simon Heller • \\ Vincent Woo · Vinay Babu · Claus Dethlefsen · Chantal Mathieu
}

Received: October 18, 2018 / Published online: December 13, 2018

(C) The Author(s) 2018

\section{ABSTRACT}

Introduction: The aim of this study was to investigate the association between baseline characteristics [HbA1c and body mass index (BMI)] and the effect of mealtime fast-acting insulin aspart (faster aspart) relative to insulin aspart (IAsp) or basal-only insulin therapy on several efficacy and safety outcomes in people with diabetes.

Enhanced digital features To view enhanced digital features for this article go to https://doi.org/10.6084/ m9.figshare.7423031.

Electronic supplementary material The online version of this article (https://doi.org/10.1007/s13300018-0553-7) contains supplementary material, which is available to authorized users.

K. Bowering $(\bowtie)$

Division of Endocrinology and Metabolism,

University of Alberta, Edmonton, AB, Canada

e-mail: keith.bowering@ualberta.ca

H. W. Rodbard

Endocrine and Metabolic Consultants, Rockville,

MD, USA

D. Russell-Jones

Diabetes and Endocrinology, Royal Surrey County

Hospital, Guildford, UK

B. Bode

Atlanta Diabetes Associates, Atlanta, GA, USA

S. Harris

Western University, London, ON, Canada
Methods: Post hoc analysis of three randomised phase $3 \mathrm{a}$ trials in people with type 1 diabetes (T1D; onset 1) and type 2 diabetes (T2D; onset 2 and 3). Participants $(N=1686)$ were stratified according to baseline BMI $\left(<25 \mathrm{~kg} / \mathrm{m}^{2}\right.$, $\left.25-<30 \mathrm{~kg} / \mathrm{m}^{2}, \geq 30 \mathrm{~kg} / \mathrm{m}^{2}\right)$ or HbA1c $(\leq 58$ $\mathrm{mmol} / \mathrm{mol},>58-<64 \mathrm{mmol} / \mathrm{mol}, \geq 64 \mathrm{mmol} /$ $\mathrm{mol} ; \leq 7.5 \%,>7.5-<8.0 \%, \geq 8.0 \%)$.

Results: In participants with T2D, the estimated treatment difference for change in HbA1c was similar for all BMI and HbA1c subgroups. No major differences between treatments were observed in risk of overall hypoglycaemia or insulin dose across subgroups. In participants with $\mathrm{T} 1 \mathrm{D}$, change in HbA1c was similar across BMI and HbA1c subgroups, and no major differences between treatments were observed for severe or blood

\section{Piletic}

General Hospital, Novo Mesto, Slovenia

\section{S. Heller}

Academic Unit of Diabetes, Endocrinology and Metabolism, University of Sheffield, Sheffield, UK

\section{Woo}

Section of Endocrinology and Metabolism,

University of Manitoba, Winnipeg, MB, Canada

V. Babu · C. Dethlefsen

Novo Nordisk A/S, Søborg, Denmark

C. Mathieu

Clinical and Experimental Endocrinology,

University Hospital Leuven, Catholic University of Leuven, Leuven, Belgium 
glucose-confirmed hypoglycaemia across subgroups. Total daily insulin dose $(\mathrm{U} / \mathrm{kg})$ was similar across all baseline HbA1c groups and the BMI $<25 \mathrm{~kg} / \mathrm{m}^{2}$ and $25-30 \mathrm{~kg} / \mathrm{m}^{2}$ groups, but was significantly lower with mealtime faster aspart compared with IAsp in the BMI $>30 \mathrm{~kg} / \mathrm{m}^{2}$ subgroup.

Conclusions: In participants with T1D and $\mathrm{T} 2 \mathrm{D}$, treatment differences (for change in HbA1c and overall hypoglycaemia) between mealtime faster aspart and insulin comparators were similar to the corresponding overall analysis across baseline HbA1c and BMI subgroups. The finding of a lower total daily insulin dose in participants with obesity (BMI $>30 \mathrm{~kg} / \mathrm{m}^{2}$ ) and T1D treated with faster aspart, versus those treated with IAsp, may warrant further investigation.

Trial Registration: ClinicalTrials.gov NCT0183 1765 (onset 1); NCT01819129 (onset 2); NCT01850615 (onset 3).

Funding: Novo Nordisk A/S, Søborg, Denmark.

Keywords: Diabetes mellitus, type 1; Diabetes mellitus, type 2; Haemoglobin A, glycosylated; Index, body mass; Insulin aspart; Outcome, treatment

\section{INTRODUCTION}

Achieving recommended HbA1c targets of 48$58 \mathrm{mmol} / \mathrm{mol}(6.5-7.5 \%)$ remains a shared challenge for people with either type 1 diabetes (T1D) or type 2 diabetes (T2D) [1]. With a view to reducing risk and slowing the development of long-term complications, basal-bolus insulin therapy in both T1D and T2D aims to mimic physiological insulin secretion. A particular focus is placed on the reduction of postprandial hyperglycaemia, which is an essential requirement for achieving overall glycaemic control $[1,2]$. Rapid-acting insulin analogues (RAIA) were developed to provide superior pharmacological action compared with regular human insulin; however, there remains an unmet need for even faster-acting mealtime insulins that can more closely mimic physiological earlyphase insulin secretion than previously available RAIA [3]. Fast-acting insulin aspart (faster aspart) is conventional insulin aspart (IAsp) in a new formulation with two added excipients (Larginine and niacinamide) and has been shown to have an earlier onset of appearance, a twotimes higher early insulin exposure and a $74 \%$ greater early glucose-lowering effect within 30 min compared with IAsp [4].

Three confirmatory randomised clinical trials-onset 1 , onset 2 and onset 3 -evaluated the efficacy and safety of faster aspart as part of a basal-bolus regimen in adults with T1D (onset 1 [5]) and T2D (onset 2 [6] and onset 3 [7]). In onset $1, \mathrm{HbA} 1 \mathrm{c}$ was statistically significantly reduced from baseline to end of trial with mealtime faster aspart versus mealtime IAsp, and faster aspart showed superior postprandial plasma glucose (PPG) control (in terms of the 2-h PPG increment after a standardised meal test) [5]. In the onset 2 trial, mealtime faster aspart was non-inferior to mealtime IAsp in change in HbA1c from baseline, and the 1-h PPG increment after a standardised meal test was significantly improved versus IAsp. In both studies, the incidence of overall severe or blood glucose (BG)-confirmed hypoglycaemia and the increase in body weight from baseline observed at the end of trial were comparable between treatments [6]. In onset 3, adding faster aspart to basal insulin resulted in superior efficacy in reducing HbA1c and statistically significantly improved PPG control, compared with basalonly insulin therapy (BOT). As might be expected, higher rates of overall severe or BGconfirmed hypoglycaemia and a statistically significant increase in body weight were observed in the faster aspart group compared with the BOT group [7].

Generally, treatment effects observed in clinical trials are not homogenous across study populations. Previous studies have demonstrated that baseline characteristics related to the severity of disease can be predictors of the HbA1c-lowering effect of insulin treatment [8]. For instance, baseline $\mathrm{HbA1c}$ has been shown to predict $\mathrm{HbA1c}$ reduction following both continuous subcutaneous insulin infusion and multiple daily injection therapy in participants with T1D $[9,10]$. Furthermore, in participants with T2D, lower baseline HbA1c has been shown to be the best clinical predictor of 
achieving HbA1c $\leq 53 \mathrm{mmol} / \mathrm{mol}(\leq 7.0 \%)$ and is also associated with a higher risk of BG-confirmed hypoglycaemia when titrating basal insulin [11]. HbA1c over 4 years has also been shown to be predominately determined by HbA1c prior to commencing basal insulin therapy [12], and higher baseline body mass index (BMI) and HbA1c have been independently associated with $\mathrm{HbA} 1 \mathrm{c} \geq 53 \mathrm{mmol} / \mathrm{mol}$ ( $\geq 7.0 \%$ ) following basal insulin treatment [8].

The aim of this post hoc analysis of the onset 1, 2 and 3 studies was to examine the association between baseline characteristics (HbA1c and BMI) and the treatment differences observed with mealtime faster aspart (in combination with basal insulin) and study comparators (basal insulin with or without mealtime IAsp) with regard to HbA1c, hypoglycaemia, body weight and insulin dose.

\section{METHODS}

\section{Study Characteristics}

The onset 1, 2 and 3 trials were phase 3, randomised, multinational, parallel-group, treatto-target studies with the overall aim of investigating the efficacy and safety of faster aspart in a basal-bolus regimen in adults with T1D and T2D. Full methodology details and results of the trials have been published elsewhere [5-7]. A top-line summary of the trials and treatment titration algorithms can be found in the Supplementary Material (Table S1). Change from baseline in end-of-trial HbA1c (primary endpoint) was measured at week 26 in onset 1 and 2 , and at week 18 in onset 3 . onset 1 included an additional 26-week treatment period [13] but these results were not included in the post hoc analysis as they were not available when the analysis was conducted. The HbA1c and BMI inclusion criteria were HbA1c 7.0-9.5\% (53$80 \mathrm{mmol} / \mathrm{mol}$ ) (onset 1 and onset 2) or $7.5-9.5 \% \quad(58-80 \mathrm{mmol} / \mathrm{mol}) \quad$ (onset 3 ); $\mathrm{BMI} \leq 35 \mathrm{~kg} / \mathrm{m}^{2}$ (onset 1 and onset 3 ) or $\leq 40 \mathrm{~kg} / \mathrm{m}^{2}$ (onset 2 ).

The three studies met the following inclusion criteria for the post hoc analysis: conducted in more than one country with a population consisting of participants with T1D or T2D; included a mealtime faster aspart treatment arm with a treatment period of at least 3 months; HbA1c measured at baseline (before the study drug was administered) and at least once after baseline (after the study drug was administered); and study endpoints included total daily insulin dose, change in body weight and rates of hypoglycaemia.

\section{Post Hoc Analysis}

In this post hoc analysis, participants were stratified according to baseline BMI $\left(<25 \mathrm{~kg} / \mathrm{m}^{2}\right.$ [underweight to normal weight], $25-<30 \mathrm{~kg} / \mathrm{m}^{2}$ [pre-obese], $\geq 30 \mathrm{~kg} / \mathrm{m}^{2}$ [obese]) [14] or HbA1c $(\leq 58 \mathrm{mmol} / \mathrm{mol},>58-<64 \mathrm{mmol} / \mathrm{mol}, \geq 64$ $\mathrm{mmol} / \mathrm{mol} ; \leq 7.5 \%, \quad>7.5-<8.0 \%, \geq 8.0 \%)$. Herein, we investigated the association between these two baseline characteristics (HbA1c and BMI) and end-of-trial treatment differences of mealtime faster aspart versus mealtime IAsp, both part of a basal-bolus regimen (onset 1 and 2 ), or mealtime faster aspart in a basal-bolus regimen versus BOT (onset 3). For onset 1, only the mealtime faster aspart and IAsp treatment arms were included, with the post-meal faster aspart arm excluded from the analysis [5].

Clinical outcomes selected for the analysis were change from baseline in $\mathrm{HbA1c}$, total daily insulin dose, rate of treatment-emergent severe or BG-confirmed hypoglycaemic episodes, and change from baseline in body weight. Hypoglycaemic episodes were categorised as treatment-emergent if the onset occurred on the first day of exposure to the study drug and no later than 1 day after the last day of randomised treatment. Severe hypoglycaemia was defined according to the American Diabetes Association classification [15] and BG-confirmed hypoglycaemia by a plasma glucose value $<3.1 \mathrm{mmol} / \mathrm{L}$ $(56 \mathrm{mg} / \mathrm{dL})$ with or without symptoms consistent with hypoglycaemia.

\section{Compliance with Ethics Guidelines}

All procedures performed in studies involving human participants were in accordance with the ethical standards of the institutional and/or 
national research committee and with the 1964 Helsinki declaration and its later amendments or comparable ethical standards. Informed consent was obtained from all individual participants included in the study.

\section{Statistical Analysis}

To estimate the treatment differences for BMI and HbA1c subgroups in change from baseline in $\mathrm{HbA1c}$, the primary analyses from onset 1, 2 and 3 [mixed model for repeated measurements (MMRM) including treatment, strata, region and baseline covariate] were modified by including the subgroup and subgroup-by-treatment interaction terms in the model. A similar model was used for change from baseline in body weight and for log-transformed doses. The dose treatment ratios were analysed using a model for log dose similar to the model for change in HbA1c, but with log dose at baseline as covariate. Treatment ratios for hypoglycaemic events were analysed using a negative binomial model for hypoglycaemic episode counts. The model used a log link and the logarithm of the exposure time as offset and included treatment, strata, region, subgroup and subgroup-by-treatment interaction. Estimated treatment differences (ETDs) are presented for each subgroup with $95 \%$ confidence intervals (CI). A significance level of $5 \%$ was used.

\section{RESULTS}

The current analysis reports data from 1686 participants across the three studies; their baseline characteristics are described in Table 1. With regard to baseline HbA1c, the majority of participants in onset 1 had $\mathrm{HbA} 1 \mathrm{c} \leq 58$ $\mathrm{mmol} / \mathrm{mol}(\leq 7.5 \%)$, while in onset 2 and 3 , the majority of participants had $\mathrm{HbA} 1 \mathrm{c} \geq 64$ $\mathrm{mmol} / \mathrm{mol}(\geq 8.0 \%)$. For baseline BMI, the majority of participants in onset 1 had BMI $25-<30 \mathrm{~kg} / \mathrm{m}^{2}$, whereas the majority of participants in both onset 2 and onset 3 had BMI $\geq 30 \mathrm{~kg} / \mathrm{m}^{2}$ (Table 1) [5-7].

The efficacy and safety results of onset 1, 2 and 3 have been reported in full elsewhere
[5-7]. Briefly, the results of these trials indicated a similar or superior reduction in HbA1c with mealtime faster aspart when compared with the comparator treatments over 18 and 26 weeks. In the current analysis, the treatment differences in the change in HbA1c remained statistically significantly in favour of faster aspart compared with IAsp across BMI and HbA1c subgroups in onset 1 (except for baseline $B M I \geq 30 \mathrm{~kg} / \mathrm{m}^{2}$ and $\mathrm{HbA} 1 \mathrm{c} \geq 64 \mathrm{mmol} / \mathrm{mol}$ ) and onset 3 . The treatment differences in change in HbA1c were not statistically significantly different with faster aspart compared with IAsp across all BMI and HbA1c subgroups in onset 2 (Fig. 1).

In onset 1 and onset 2 , no statistically significant difference was observed in the rate of severe or BG-confirmed hypoglycaemia between treatment groups, while in onset 3 , as expected, the incidence of severe or BG-confirmed hypoglycaemia was significantly greater in the faster aspart group compared with the BOT group [5-7]. In the current analysis, a numerically higher rate of severe or BG-confirmed hypoglycaemic episodes was observed in participants with baseline $\mathrm{BMI}>30 \mathrm{~kg} / \mathrm{m}^{2}$ receiving faster aspart compared with IAsp in onset 1 , and no other differences of clinical interest in severe or BG-confirmed hypoglycaemia were observed across subgroups in onset 2 and 3 (Fig. 2).

In onset 1 and 2 , there was no difference in the geometric mean daily total insulin dose at the end of the trial between treatment arms $[5,6]$, while in onset 3 , as expected, the geometric mean daily total insulin dose was higher in the faster aspart group compared with the BOT group (ratio [95\% CI], $1.85 \mathrm{U} / \mathrm{kg}$ $[1.65 ; 2.07])$ [7]. In the current analysis, in onset 1 , there was a significantly lower total daily insulin dose in units per kilogram (mealtime faster aspart/mealtime IAsp) observed in participants with baseline $\mathrm{BMI} \geq 30 \mathrm{~kg} / \mathrm{m}^{2}$ (ratio [95\% CI], $0.82 \mathrm{U} / \mathrm{kg}$ [0.71; 0.93]) (Fig. 3). There were no other major differences observed between treatments for the end-of-trial geometric mean total daily insulin dose in units per kilogram across subgroups in onset 2 and 3 (Fig. 3).

In the three studies, the mean body weight at the end of trial increased from baseline across all treatment arms [5-7]. In onset 1 and 2, there 


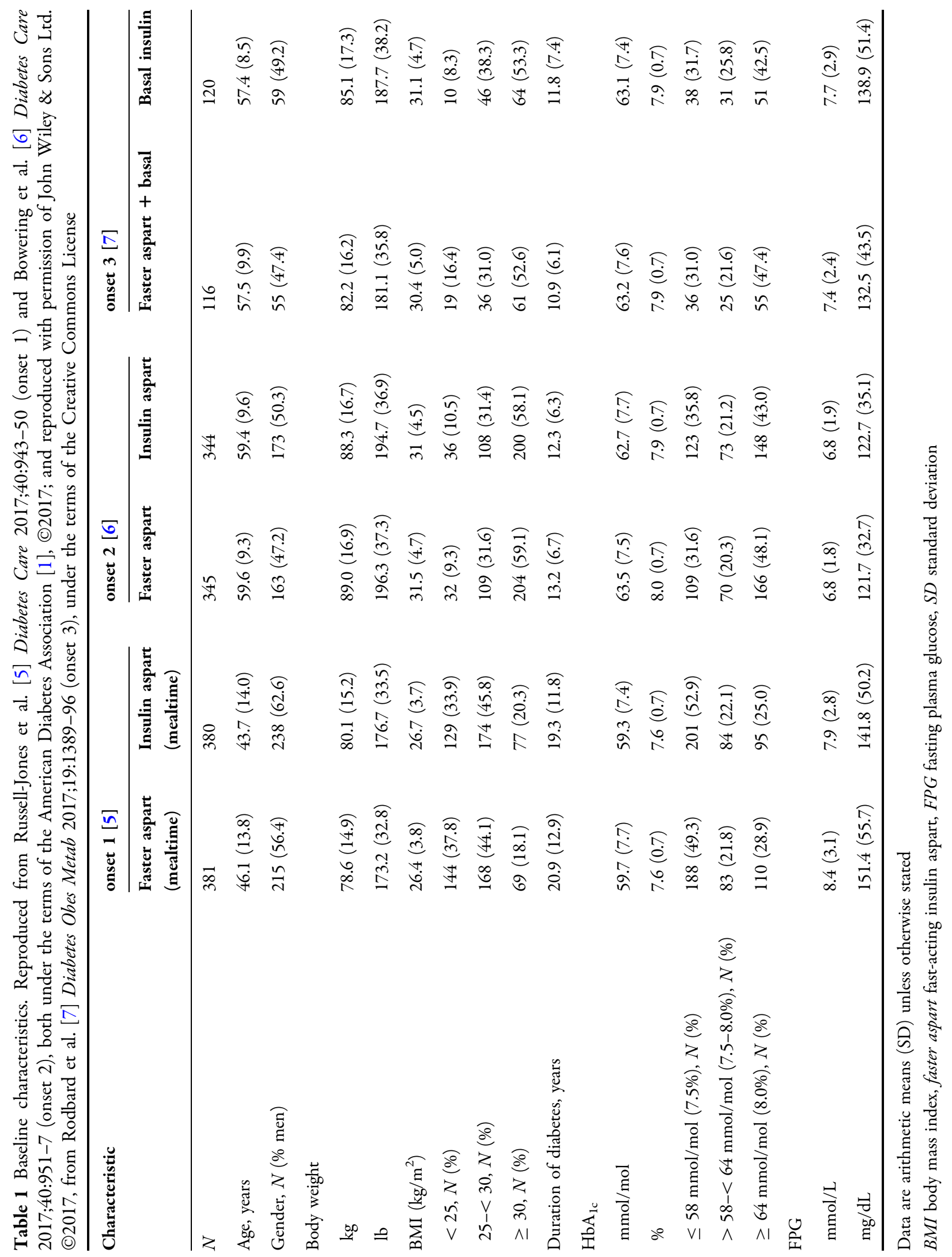


(a)

All participants* $(\mathrm{N}=381 / 380)$

$\mathrm{BMI}<25 \mathrm{~kg} / \mathrm{m}^{2}(\mathrm{~N}=144 / 129)$

BMI $25-<30 \mathrm{~kg} / \mathrm{m}^{2}(\mathrm{~N}=168 / 1074)$

$\mathrm{BMI} \geq 30 \mathrm{~kg} / \mathrm{m}^{2}(\mathrm{~N}=69 / 77)$

$\mathrm{HbA} 1 \mathrm{c} \leq 58 \mathrm{mmol} / \mathrm{mol}(\leq 7.5 \%)(\mathrm{N}=188 / 201)$

$\mathrm{HbA} 1 \mathrm{c}>58-<64 \mathrm{mmol} / \mathrm{mol}(>7.5-<8.0 \%)(\mathrm{N}=83 / 84)$

$\mathrm{HbA} 1 \mathrm{c} \geq 64 \mathrm{mmol} / \mathrm{mol}(\geq 8.0 \%)(\mathrm{N}=110 / 95)$

(b)

All participants ${ }^{\dagger}(\mathrm{N}=341 / 341)$

BMI $<25 \mathrm{~kg} / \mathrm{m}^{2}(\mathrm{~N}=32 / 35)$

BMI $25-<30 \mathrm{~kg} / \mathrm{m}^{2}(\mathrm{~N}=106 / 107)$

$\mathrm{BMI} \geq 30 \mathrm{~kg} / \mathrm{m}^{2}$ ( $\left.\mathrm{N}=203 / 199\right)$

$\mathrm{HbA} 1 \mathrm{c} \leq 58 \mathrm{mmol} / \mathrm{mol}(\leq 7.5 \%)(\mathrm{N}=108 / 120)$

$\mathrm{HbA} 1 \mathrm{c}>58-<64 \mathrm{mmol} / \mathrm{mol}(>7.5-<8.0 \%)(\mathrm{N}=70 / 73)$

$\mathrm{HbA} 1 \mathrm{c} \geq 64 \mathrm{mmol} / \mathrm{mol}(\geq 8.0 \%)(\mathrm{N}=163 / 148)$

(c)

All participants ${ }^{\ddagger}(\mathrm{N}=120 / 115)$

$\mathrm{BMl}<25 \mathrm{~kg} / \mathrm{m}^{2}(\mathrm{~N}=10 / 19)$

BMI $25-<30 \mathrm{~kg} / \mathrm{m}^{2}(\mathrm{~N}=46 / 35)$

$\mathrm{BMI} \geq 30 \mathrm{~kg} / \mathrm{m}^{2}(\mathrm{~N}=64 / 61)$

$\mathrm{HbA} 1 \mathrm{c} \leq 58 \mathrm{mmol} / \mathrm{mol}(\leq 7.5 \%)(\mathrm{N}=38 / 36)$

$\mathrm{HbA} 1 \mathrm{c}>58-<64 \mathrm{mmol} / \mathrm{mol}(>7.5-<8.0 \%)(\mathrm{N}=31 / 25)$

$\mathrm{HbA} 1 \mathrm{c} \geq 64 \mathrm{mmol} / \mathrm{mol}(\geq 8.0 \%)(\mathrm{N}=51 / 54)$ onset 1 (T1D):

Faster aspart - insulin aspart

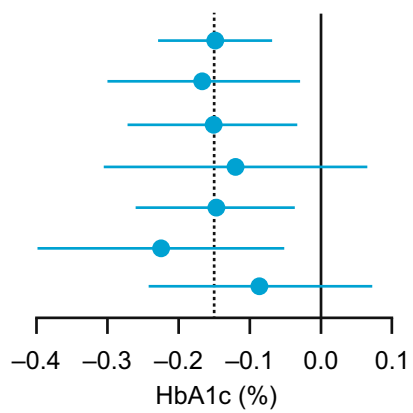

onset 2 (T2D):

Faster aspart - insulin aspart

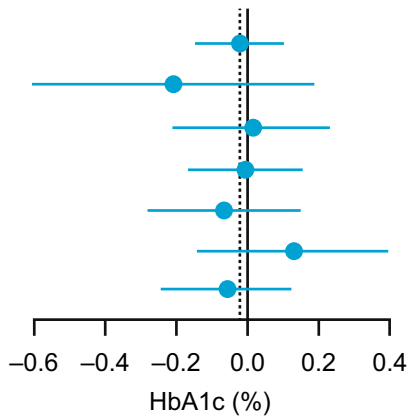

onset 3 (T2D):

(Faster aspart + basal) - (basal only)

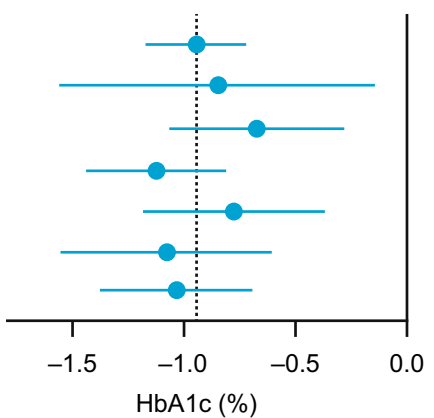

Change in $\mathrm{HbA} 1 \mathrm{c}$ after 26 weeks $\operatorname{ETD}(95 \% \mathrm{Cl})$

$-0.15(-0.23 ;-0.07)$

$-0.16(-0.30 ;-0.03)$

$-0.15(-0.27 ;-0.03)$

$-0.12(-0.31 ; 0.07)$

$-0.15(-0.26 ;-0.04)$

$-0.23(-0.40 ;-0.05)$

$-0.08(-0.24 ; 0.07)$

Change in $\mathrm{HbA} 1 \mathrm{c}$ after 26 weeks ETD $(95 \% \mathrm{Cl})$

$-0.02(-0.15 ; 0.10)$

$-0.21(-0.61 ; 0.19)$

$0.01(-0.21 ; 0.23)$

$-0.01(-0.17 ; 0.16)$

$-0.07(-0.28 ; 0.15)$

$0.13(-0.14 ; 0.40)$

$-0.06(-0.24 ; 0.12)$

Change in $\mathrm{HbA} 1 \mathrm{c}$ after 18 weeks ETD $(95 \% \mathrm{Cl})$

$-0.94(-1.17 ;-0.72)$

$-0.85(-1.55 ;-0.15)$

$-0.67(-1.06 ;-0.28)$

$-1.12(-1.43 ;-0.81)$

$-0.77(-1.18 ;-0.37)$

$-1.07(-1.54 ;-0.61)$

$-1.03(-1.37 ;-0.69)$
Fig. 1 Estimated treatment differences for the change in $\mathrm{HbAlc}$ from baseline according to baseline BMI and HbAlc subgroup in a onset $1, \mathbf{b}$ onset 2 , and $\mathbf{c}$ onset 3 trials. $\mathrm{N}$ (faster aspart/comparator). Data from full analysis set. ETD (faster aspart arm - comparator). Dotted vertical line represents the ETD for all participants. Changes in $\mathrm{HbAlc}(\mathrm{mmol} / \mathrm{mol}[\%])$ from baseline at the end of trial for the total study population in onset 1,2 and 3 have previously been reported [5-7]: ${ }^{*}$ mealtime faster aspart $(-3.46 \mathrm{mmol} / \mathrm{mol}[-0.32 \%])$, mealtime insulin aspart $(-1.84 \mathrm{mmol} / \mathrm{mol}[-0.17 \%]) ;{ }^{\dagger}$ mealtime faster aspart $(-15.10 \mathrm{mmol} / \mathrm{mol}[-1.38 \%])$, mealtime insulin aspart $(-14.86 \mathrm{mmol} / \mathrm{mol}[-1.36 \%]) ;{ }^{\ddagger}$ mealtime faster aspart + basal insulin $(-12.72 \mathrm{mmol} / \mathrm{mol}[-1.16 \%])$, basal-only insulin $(-2.43 \mathrm{mmol} / \mathrm{mol}[-0.22 \%]) . B G$ blood glucose, $B M I$ body mass index, $C I$ confidence interval, ETD estimated treatment difference, faster aspart fast-acting insulin aspart, $N$ number of participants, $T 1 D$ type 1 diabetes, $T 2 D$ type 2 diabetes 
(a)

All participants* $(\mathrm{N}=381 / 380)$

$\mathrm{BMI}<25 \mathrm{~kg} / \mathrm{m}^{2}(\mathrm{~N}=144 / 129)$

BMI $25-<30 \mathrm{~kg} / \mathrm{m}^{2}(\mathrm{~N}=168 / 1074)$

$\mathrm{BMI} \geq 30 \mathrm{~kg} / \mathrm{m}^{2}(\mathrm{~N}=69 / 77)$

$\mathrm{HbA} 1 \mathrm{c} \leq 58 \mathrm{mmol} / \mathrm{mol}(\leq 7.5 \%)(\mathrm{N}=188 / 201)$

$\mathrm{HbA} 1 \mathrm{c}>58-<64 \mathrm{mmol} / \mathrm{mol}(>7.5-<8.0 \%)(\mathrm{N}=83 / 84)$

$\mathrm{HbA} 1 \mathrm{c} \geq 64 \mathrm{mmol} / \mathrm{mol}(\geq 8.0 \%)(\mathrm{N}=110 / 95)$ onset 1 (T1D):

Faster aspart/insulin aspart

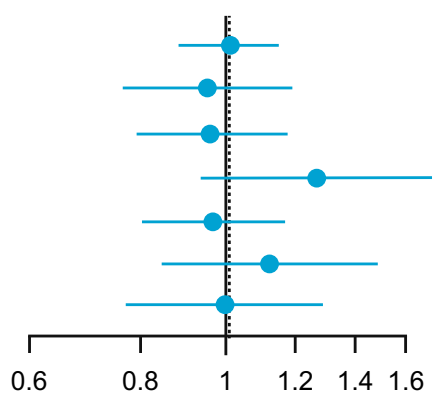

Severe or BG-confirmed hypoglycaemia (events per patient-year)

(b)

All participants ${ }^{\dagger}(\mathrm{N}=341 / 341)$

$\mathrm{BMI}<25 \mathrm{~kg} / \mathrm{m}^{2}(\mathrm{~N}=32 / 35)$

BMI 25-<30 kg/m² (N=106/107)

$\mathrm{BMI} \geq 30 \mathrm{~kg} / \mathrm{m}^{2}(\mathrm{~N}=203 / 199)$

$\mathrm{HbA} 1 \mathrm{c} \leq 58 \mathrm{mmol} / \mathrm{mol}(\leq 7.5 \%)(\mathrm{N}=108 / 120)$

$\mathrm{HbA} 1 \mathrm{c}>58-<64 \mathrm{mmol} / \mathrm{mol}(>7.5-<8.0 \%)(\mathrm{N}=70 / 73)$

$\mathrm{HbA} 1 \mathrm{c} \geq 64 \mathrm{mmol} / \mathrm{mol}(\geq 8.0 \%)(\mathrm{N}=163 / 148)$

onset 2 (T2D):

Faster aspart/insulin aspart

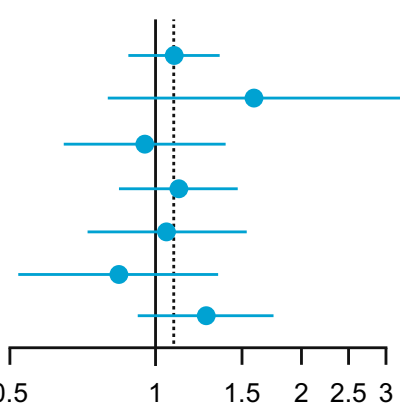

Severe or BG-confirmed hypoglycaemia (events per patient-year)

(c)

All participants $\left.\mathrm{s}^{\ddagger} \mathrm{N}=120 / 115\right)$

$\mathrm{BMl}<25 \mathrm{~kg} / \mathrm{m}^{2}(\mathrm{~N}=10 / 19)$

BMI $25-<30 \mathrm{~kg} / \mathrm{m}^{2}(\mathrm{~N}=46 / 35)$

$\mathrm{BMI} \geq 30 \mathrm{~kg} / \mathrm{m}^{2}(\mathrm{~N}=64 / 61)$

$\mathrm{HbA} 1 \mathrm{c} \leq 58 \mathrm{mmol} / \mathrm{mol}(\leq 7.5 \%)(\mathrm{N}=38 / 36)$

$\mathrm{HbA} 1 \mathrm{c}>58-<64 \mathrm{mmol} / \mathrm{mol}(>7.5-<8.0 \%)(\mathrm{N}=31 / 25)$

$\mathrm{HbA} 1 \mathrm{c} \geq 64 \mathrm{mmol} / \mathrm{mol}(\geq 8.0 \%)(\mathrm{N}=51 / 54)$ onset 3 (T2D):

(Faster aspart + basal)/(basal only)

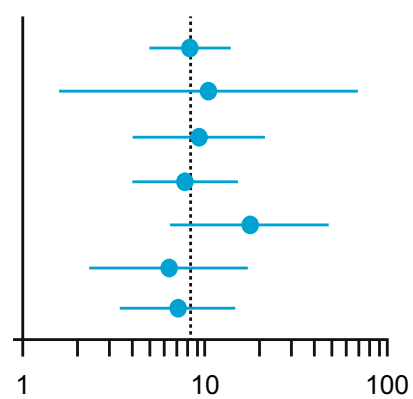

Rate ratio

$(95 \% \mathrm{Cl})$

$1.01(0.88 ; 1.15)$

$0.95(0.76 ; 1.19)$

$0.96(0.79 ; 1.17)$

$1.27(0.93 ; 1.72)$

$0.97(0.80 ; 1.16)$

$1.12(0.84 ; 1.49)$

$1.00(0.77 ; 1.29)$
$(95 \% \mathrm{Cl})$

$1.09(0.88 ; 1.36)$

$1.60(0.80 ; 3.20)$

$0.95(0.65 ; 1.40)$

$1.11(0.84 ; 1.48)$

$1.05(0.72 ; 1.54)$

$0.84(0.52 ; 1.35)$

$1.27(0.92 ; 1.75)$

Rate ratio

$(95 \% \mathrm{Cl})$

$8.24(4.95 ; 13.73)$

$10.40(1.59 ; 67.95)$

$9.25(4.05 ; 21.09)$

$7.78(4.02 ; 15.05)$

$17.39(6.42 ; 47.09)$

$6.26(2.31 ; 16.99)$

$7.06(3.41 ; 14.59)$

Severe or BG-confirmed hypoglycaemia (events per patient-year)

Fig. 2 Severe or BG-confirmed hypoglycaemia rate ratios according to baseline BMI and $\mathrm{HbAlc}$ subgroup in a onset 1 , $\mathbf{b}$ onset 2, and $\mathbf{c}$ onset 3 trials. $\mathrm{N}$ (faster aspart/comparator). Data from full analysis set. Rate ratio (faster aspart arm/comparator). An episode that is severe (requiring assistance of another person to actively administer carbohydrate or glucagon, or take other corrective actions) or BG-confirmed by a blood glucose value $<3.1 \mathrm{mmol} / \mathrm{L}$ $(56 \mathrm{mg} / \mathrm{dL})$ with or without symptoms consistent with hypoglycaemia. Dotted vertical line represents the rate ratio for all participants. Severe or BG-confirmed hypoglycaemic events per patient-year of exposure for each treatment in the total study population in onset 1,2 and 3 have previously been reported [5-7]: * ${ }^{*}$ ealtime faster aspart (59.0), mealtime insulin aspart (58.7); ${ }^{\dagger}$ mealtime faster aspart (17.8), mealtime insulin aspart (16.6); ${ }^{\ddagger}$ mealtime faster aspart + basal insulin (12.8), basal-only insulin (2.0). $B G$ blood glucose, $B M I$ body mass index, $C I$ confidence interval, faster aspart fast-acting insulin aspart, $N$ number of participants, TID type 1 diabetes, $T 2 D$ type 2 diabetes 
(a)

All participants* $(\mathrm{N}=381 / 380)$

$\mathrm{BMI}<25 \mathrm{~kg} / \mathrm{m}^{2}(\mathrm{~N}=144 / 129)$

BMI $25-<30 \mathrm{~kg} / \mathrm{m}^{2}(\mathrm{~N}=168 / 1074)$

$\mathrm{BMI} \geq 30 \mathrm{~kg} / \mathrm{m}^{2}(\mathrm{~N}=69 / 77)$

$\mathrm{HbA} 1 \mathrm{c} \leq 58 \mathrm{mmol} / \mathrm{mol}(\leq 7.5 \%)(\mathrm{N}=188 / 201)$

$\mathrm{HbA} 1 \mathrm{c}>58-<64 \mathrm{mmol} / \mathrm{mol}(>7.5-<8.0 \%)(\mathrm{N}=83 / 84)$

$\mathrm{HbA} 1 \mathrm{c} \geq 64 \mathrm{mmol} / \mathrm{mol}(\geq 8.0 \%)(\mathrm{N}=110 / 95)$

(b)

All participants ${ }^{\dagger}(\mathrm{N}=341 / 341)$

BMI $<25 \mathrm{~kg} / \mathrm{m}^{2}(\mathrm{~N}=32 / 35)$

BMI $25-<30 \mathrm{~kg} / \mathrm{m}^{2}$ (N=106/107)

$\mathrm{BMI} \geq 30 \mathrm{~kg} / \mathrm{m}^{2}(\mathrm{~N}=203 / 199)$

$\mathrm{HbA} 1 \mathrm{c} \leq 58 \mathrm{mmol} / \mathrm{mol}(\leq 7.5 \%)(\mathrm{N}=108 / 120)$

$\mathrm{HbA} 1 \mathrm{c}>58-<64 \mathrm{mmol} / \mathrm{mol}(>7.5-<8.0 \%)(\mathrm{N}=70 / 73)$

$\mathrm{HbA} 1 \mathrm{c} \geq 64 \mathrm{mmol} / \mathrm{mol}(\geq 8.0 \%)(\mathrm{N}=163 / 148)$

(c)

All participants $\ddagger^{\ddagger}(\mathrm{N}=120 / 115)$

$\mathrm{BMI}<25 \mathrm{~kg} / \mathrm{m}^{2}(\mathrm{~N}=10 / 19)$

BMI $25-<30 \mathrm{~kg} / \mathrm{m}^{2}(\mathrm{~N}=46 / 35)$

$\mathrm{BMI} \geq 30 \mathrm{~kg} / \mathrm{m}^{2}(\mathrm{~N}=64 / 61)$

$\mathrm{HbA} 1 \mathrm{c} \leq 58 \mathrm{mmol} / \mathrm{mol}(\leq 7.5 \%)(\mathrm{N}=38 / 36)$

$\mathrm{HbA} 1 \mathrm{c}>58-<64 \mathrm{mmol} / \mathrm{mol}(>7.5-<8.0 \%)(\mathrm{N}=31 / 25)$

$\mathrm{HbA} 1 \mathrm{c} \geq 64 \mathrm{mmol} / \mathrm{mol}(\geq 8.0 \%)(\mathrm{N}=51 / 54)$ onset 1 (T1D):

Faster aspart/insulin aspart

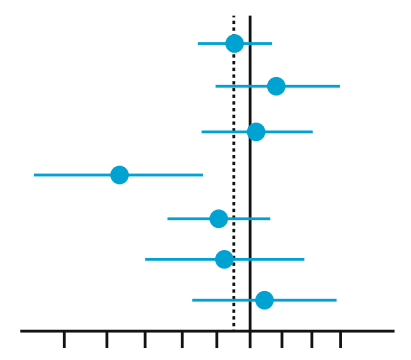

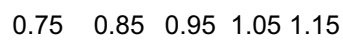

Total daily actual insulin dose (U/kg)

onset 2 (T2D):

Faster aspart/insulin aspart

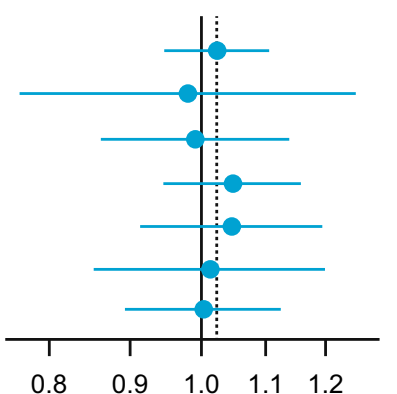

Total daily actual insulin dose $(\mathrm{U} / \mathrm{kg})$

onset 3 (T2D):

(Faster aspart + basal)/(basal only)

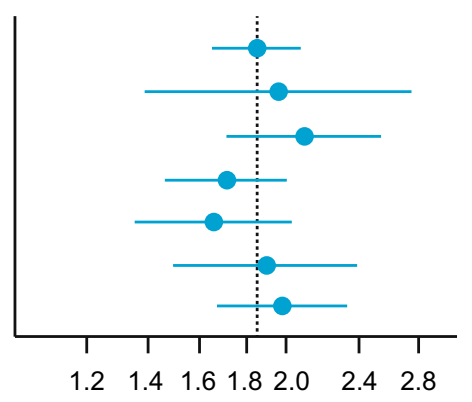

Total daily actual insulin dose (U/kg)
Dose ratio at week 26 $(95 \% \mathrm{Cl})$

$0.97(0.92 ; 1.04)$

$1.04(0.95 ; 1.15)$

$1.01(0.93 ; 1.10)$

$0.82(0.71 ; 0.93)$

$0.95(0.88 ; 1.03)$

$0.96(0.85 ; 1.09)$

$1.02(0.91 ; 1.14)$

Dose ratio at week 26 (95\% Cl)

$1.02(0.95 ; 1.11)$

$0.98(0.77 ; 1.25)$

$0.99(0.86 ; 1.14)$

$1.05(0.95 ; 1.16)$

$1.04(0.91 ; 1.19)$

$1.01(0.85 ; 1.20)$

$1.00(0.89 ; 1.12)$

Dose ratio at week 18 $(95 \% \mathrm{Cl})$

$1.85(1.65 ; 2.07)$

$1.95(1.39 ; 2.75)$

$2.09(1.72 ; 2.54)$

$1.71(1.46 ; 2.00)$

$1.66(1.35 ; 2.02)$

$1.89(1.50 ; 2.39)$

$1.97(1.67 ; 2.33)$
Fig. 3 Total daily insulin dose $(\mathrm{U} / \mathrm{kg})$ ratios according to baseline BMI and HbAlc subgroups in a onset $1, \mathbf{b}$ onset 2 , and $\mathbf{c}$ onset 3 trials. $\mathrm{N}$ (faster aspart/comparator). Data from full analysis set. Dose ratio (faster aspart arm/comparator). Dotted vertical line represents the dose ratio for all participants. Median total daily insulin dose $(\mathrm{U} / \mathrm{kg})$ at the end of trial for the total study population in onset 1,2 and 3 have previously been reported [5-7]: ${ }^{*}$ mealtime faster aspart $(0.80 \mathrm{U} / \mathrm{kg})$, mealtime insulin aspart $(0.83 \mathrm{U} /$ $\mathrm{kg})$; ${ }^{\dagger}$ mealtime faster aspart $(1.0 \mathrm{U} / \mathrm{kg})$, mealtime insulin aspart $(1.0 \mathrm{U} / \mathrm{kg}) ;{ }^{\dagger}$ mealtime faster aspart + basal insulin $(1.1 \mathrm{U} / \mathrm{kg})$, basal-only insulin $(0.6 \mathrm{U} / \mathrm{kg})$. BMI body mass index, $C I$ confidence interval, faster aspart fast-acting insulin aspart, $N$ number of participants, TID type 1 diabetes, $T 2 D$ type 2 diabetes 
were no statistically significant differences between treatments for change in body weight from baseline [5-7]. In onset 3 , as expected with more intensive therapy, there was a statistically significant increase in body weight from baseline in the faster aspart arm compared with the BOT arm (ETD [95\% CI], $1.66 \mathrm{~kg}[0.89 ; 2.43]$ ) [7]. In the current analysis, the ETD between treatment arms for change in body weight from baseline was not statistically significantly different between treatments in any baseline HbA1c subgroups in onset 1 and 2 (Table S2). In onset 3, the ETD for change in body weight from baseline was statistically significantly in favour of the mealtime faster aspart arm compared with the BOT arm in the baseline HbA1c $>58-<64 \mathrm{mmol} \quad(>7.5-<8 \%)$ and $\geq 64 \mathrm{mmol} / \mathrm{mol}$ ( $\geq 8 \%$ ) subgroups (Table S2).

\section{DISCUSSION}

This post hoc analysis of the onset $1-3$ clinical trials [5-7] aimed to explore, in people with T1D or T2D, the association between baseline characteristics (HbA1c and BMI) and several end-oftrial clinical outcomes when using mealtime faster aspart in a basal-bolus regimen, either versus mealtime IAsp (basal-bolus) or BOT.

In participants with T2D, baseline HbA1c and BMI subgroups were not seen to exert a clinically relevant effect on the treatment differences of the studied outcomes, and the subgroup results generally aligned with what was reported in the overall population $[6,7]$. In participants with T1D, the treatment differences in change in HbA1c across baseline HbA1c and BMI subgroups were generally similar to those reported in the overall population. However, a lower total daily insulin dose with mealtime faster aspart compared with IAsp, along with a numerically higher rate of severe or BG-confirmed hypoglycaemia, was observed in participants with baseline BMI $>30 \mathrm{~kg} / \mathrm{m}^{2}$. It is possible that the lower total daily insulin dose used by participants with baseline obesity was a behavioural response to the numerically higher rate of severe or BG-confirmed hypoglycaemia experienced following treatment with mealtime faster aspart relative to IAsp. Additionally, subcutaneous fat thickness, along with low subcutaneous adipose tissue blood flow, can delay the rate of absorption of RAIA $[16,17]$; therefore, the results indicate that the pharmacological profile of faster aspart may, to a certain degree, be less impacted by the presence of subcutaneous fat relative to IAsp. Although speculative, this suggests that people with obesity may require a lower dose of faster aspart compared with IAsp. Further, there was only a small number of participants in the baseline $\mathrm{BMI}>30 \mathrm{~kg} / \mathrm{m}^{2}$ subgroup, along with a broad CI for the dose ratio, and only participants with $\mathrm{BMI} \leq 40 \mathrm{~kg} / \mathrm{m}^{2}$ were included in the onset 1 trial. Thus, it is not clear if this effect would be observed in people with a BMI $>40 \mathrm{~kg} / \mathrm{m}^{2}$. Further exploration is needed to address the underlying physiological and behavioural factors contributing to this finding.

Generalisations from this subgroup analysis should be made with caution, but the current results could have implications for real-world treatment. Generally, clinicians may be mindful that glycaemic response, total daily insulin dose and rate of severe or BG-confirmed hypoglycaemia arising from faster aspart basal-bolus treatment may not be impacted by a patient's baseline BMI and HbA1c to any clinically relevant degree. However, in clinical practice, these baseline characteristics, in the context of a wider patient profile including social and psychological factors, may be used by clinicians to guide clinical decision-making within a patientcentred model of diabetes management [1]. For future research, it may be worth identifying other baseline factors (e.g. postprandial hyperglycaemia, duration of diabetes, frequency of self-measured blood glucose testing) that predict response to faster aspart basal-bolus treatment in people with T1D and T2D.

There are some limitations of the current analysis that should be highlighted. For example, the analysis was post hoc, and there were different numbers of participants in the subgroups, with only a small number in some subgroups. Moreover, for factors where subgroup categorisation depends on a biological measure, there is a risk of misclassification, in particular due to measurement or diagnostic error [18]. Additionally, when multiple 
subgroup analyses are performed, the risk of a false positive finding can be increased [18]. No clinical outcomes other than those reported here were explored; for measures of adiposity, only BMI and body weight were analysed.

\section{CONCLUSIONS}

In the post hoc subgroup analysis of the onset 2 and 3 trials, neither baseline HbA1c nor BMI significantly influenced the treatment differences between mealtime faster aspart and IAsp (or BOT) with regard to end-of-trial glycaemic control, overall hypoglycaemia, total daily insulin dose, or body weight in individuals with T2D. In the post hoc analysis of onset 1 , a lower total daily insulin dose with mealtime faster aspart compared with IAsp treatment was observed in participants with T1D who had baseline BMI $>30 \mathrm{~kg} / \mathrm{m}^{2}$, with no differences in glycaemic control, overall hypoglycaemia, or body weight across subgroups from the trial.

\section{ACKNOWLEDGEMENTS}

We thank all investigators, trial staff and participants of this study.

Funding. Sponsorship for this study and article processing charges were funded by Novo Nordisk A/S, Søborg, Denmark. All authors had full access to all of the data in this study and take complete responsibility for the integrity of the data and accuracy of the data analysis.

Medical Writing and Editorial Assistance. Medical writing and submission support were provided by Samuel Bestall PhD and Erin Slobodian of Watermeadow Medical, an Ashfield company, part of UDG Healthcare PLC, funded by Novo Nordisk A/S.

Authorship. All named authors meet the International Committee of Medical Journal Editors (ICMJE) criteria for authorship of this manuscript, take responsibility for the integrity of the work as a whole, and have given their approval for this version to be published.
Authorship Contributions. Keith Bowering, Helena W. Rodbard, David Russell-Jones, Bruce Bode, Stewart Harris, Milivoj Piletic, Simon Heller, Vincent Woo, Vinay Babu, Claus Dethlefsen and Chantal Mathieu all provided critical input into revised versions of the manuscript and approved the final manuscript for submission. Claus Dethlefsen carried out the statistical analysis.

Prior Presentation. The onset 1 data analysed in this manuscript have been previously published in the abstract book of the American Diabetes Association-77th Annual Scientific Sessions (ADA 2017), Orlando, FL, USA; and previously presented in poster form at International Diabetes Federation-24th World Diabetes Congress (IDF 2017), Abu Dhabi, United Arab Emirates; Societe Francaise d'Endocrinologie-34th Annual Congress (SFE 2017), Poitiers, France; Sociedade Brasileira de Diabetes-XXI Congresso (SBD 2017), Sao Paulo, Brazil; Societe Francophone du Diabete44th Congres Annuel (SFD 2018), Nantes, France; and Advanced Technologies \& Treatments for Diabetes-11th International Conference (ATTD 2018), Vienna, Austria. The onset 2 and 3 data analysed in this manuscript have been previously published in the abstract book of the American Diabetes Association77th Annual Scientific Sessions (ADA 2017), Orlando, FL, USA; and previously presented in poster form at International Diabetes Federation-24th World Diabetes Congress (IDF 2017), Abu Dhabi, United Arab Emirates; Canadian Diabetes Association/CSEM 20th Annual Professional Conference and Annual Meetings (CDA 2017), Edmonton, Canada; Sociedade Brasileira de Diabetes-XXI Congresso (SBD 2017), Sao Paulo, Brazil; Societa Italiana di Medicina Interna-118 Congresso Nazionale (SIMI 2017), Rome, Italy; and Societa Italiana di Diabetologia-Congresso 27 (SID 2018), Rimini, Italy.

Disclosures. Keith Bowering has participated in advisory panels for AstraZeneca, Boehringer Ingelheim, Eli Lilly, Merck, Novo Nordisk, Sanofi, Johnson \& Johnson; and speakers' bureau for Novo Nordisk and Sanofi. Helena W. 
Rodbard has served on advisory panels for Amylin Pharmaceuticals Inc., AstraZeneca Pharmaceuticals LP, Biodel Inc., Bayer Health Care LLC, Merck, Novo Nordisk A/S, Roche Pharmaceuticals and Sanofi; as a consultant for Biodel Inc., Merck, Roche Pharmaceuticals and Takeda Pharmaceuticals U.S.A. Inc., Merck and Sanofi; has received research support from AstraZeneca Pharmaceuticals LP, Biodel Inc., Boehringer Ingelheim Pharmaceuticals Inc., Hamni, Janssen Pharmaceuticals, Eli Lilly and Company, Merck, Novartis Pharmaceuticals Corporation, Novo Nordisk A/S, Roche Pharmaceuticals and Sanofi; and has served as a speaker for AstraZeneca Pharmaceuticals LP, BMS, Boehringer Ingelheim Pharmaceuticals Inc., Janssen, Eli Lilly and Company, Merck, Novo Nordisk A/S, Sanofi and Takeda Pharmaceuticals U.S.A. Inc. David Russell-Jones has participated in advisory panels; been a board member and consultant for AstraZeneca, Sanofi Aventis, Lilly, and Novo Nordisk; received research support from AstraZeneca, Sanofi Aventis, Novartis, and Novo Nordisk; and participated in speakers' bureaus for AstraZeneca, Sanofi Aventis, Lilly, Novo Nordisk, Janssen, Takeda, and Boehringer Ingelheim. Bruce Bode has participated in advisory panels for Novo Nordisk, Sanofi, and Adocia; has been a consultant for Medtronic, Sanofi, and Novo Nordisk; received research support from Abbott, Boehringer Ingelheim/Lilly, BD, DexCom, Janssen, Lexicon, Medtronic, Novo Nordisk, Sanofi, and Sensonics; participated in speakers' bureaus for AstraZeneca, Insulet, Janssen, Medtronic, Novo Nordisk and Sanofi; and holds stock in Glytec. Stewart Harris has received research support from Novo Nordisk, Sanofi, Merck, Abbott, Janssen and AstraZeneca; has served on an advisory panel for Novo Nordisk, Sanofi, Merck, AstraZeneca, Lilly/BI, Amgen, Abbott and Janssen; has served as a consultant for Novo Nordisk, Sanofi, Merck, Abbott, Janssen and AstraZeneca and/or other in-kind services for CIHR, CDA, The Lawson Foundation. Milivoj Piletic has participated in advisory panels for Novo Nordisk, Boehringer Ingelheim and Eli Lilly. Simon Heller has participated in advisory panels for Eli Lilly \& Co, Novo Nordisk A/S, Takeda, Boehringher Ingelheim, Zealand, UN-EEG; and speakers' bureau for Novo Nordisk, Eli Lilly \& Co, Merck Sharp \& Dohme, AstraZeneca. Vincent Woo has received personal fees in relation to speakers' fees and advisory board activities from Novo Nordisk, Eli Lilly, Sanofi, AstraZeneca, Boehringer Ingelheim and Merck; he also reports serving as an investigator for clinical trials sponsored by Merck, Novo Nordisk, Eli Lilly, Sanofi, AstraZeneca, Boehringer Ingelheim, GlaxoSmithKline and Locemia Solutions. Vinay $\mathrm{Babu}$ is an employee of Novo Nordisk A/S. Claus Dethlefsen is an employee of Novo Nordisk A/S and owns stocks and shares in Novo Nordisk A/S. Chantal Mathieu has participated in advisory panels for Novo Nordisk, Sanofi-Aventis, Merck Sharp \& Dohme Ltd., Eli Lilly and Company, Novartis, AstraZeneca LP, Jansen Pharmaceuticals, Hanmi Pharmaceuticals, Intrexon, Boehringer Ingelheim; received research support from Novo Nordisk, Sanofi-Aventis, Merck Sharp \& Dohme Ltd., Boehringer Ingelheim; and has participated in speakers' bureaus for Novo Nordisk, Sanofi-Aventis, Merck Sharp \& Dohme, Eli Lilly and Company, Novartis, AstraZeneca.

Compliance with Ethics Guidelines. All procedures performed in studies involving human participants were in accordance with the ethical standards of the institutional and/or national research committee and with the 1964 Helsinki declaration and its later amendments or comparable ethical standards. Informed consent was obtained from all individual participants included in the study.

Data Availability. The datasets generated during and/or analyzed during the current study are available from the corresponding author on reasonable request.

Open Access. This article is distributed under the terms of the Creative Commons Attribution-NonCommercial 4.0 International License (http://creativecommons.org/licenses/ by-nc/4.0/), which permits any noncommercial use, distribution, and reproduction in any medium, provided you give appropriate credit to the original author(s) and the source, provide a link to the Creative Commons license, and indicate if changes were made. 


\section{REFERENCES}

1. American Diabetes Association. Standards of medical care in diabetes-2017. Diabetes Care. 2017;40:S1-135.

2. Monnier L, Lapinski H, Colette C. Contributions of fasting and postprandial plasma glucose increments to the overall diurnal hyperglycemia of type 2 diabetic patients: variations with increasing levels of $\operatorname{HbA}(1 \mathrm{c})$. Diabetes Care. 2003;26:881-5.

3. Mathieu C, Gillard P, Benhalima K. Insulin analogues in type 1 diabetes mellitus: getting better all the time. Nat Rev Endocrinol. 2017;13:385-99.

4. Heise T, Pieber TR, Danne T, Erichsen L, Haahr H. A pooled analysis of clinical pharmacology trials investigating the pharmacokinetic and pharmacodynamic characteristics of fast-acting insulin aspart in adults with type 1 diabetes. Clin Pharmacokinet. 2017;56:551-9.

5. Russell-Jones D, Bode BW, De Block C, et al. Fastacting insulin aspart improves glycemic control in basal-bolus treatment for type 1 diabetes: results of a 26-week multicenter, active-controlled, treat-totarget, randomized, parallel-group trial (onset 1). Diabetes Care. 2017;40:943-50.

6. Bowering K, Case C, Harvey J, et al. Faster aspart versus insulin aspart as part of a basal-bolus regimen in inadequately controlled type 2 diabetes: the onset 2 trial. Diabetes Care. 2017;40:951-7.

7. Rodbard HW, Tripathy D, Vidrio Velazquez M, Demissie M, Tamer SC, Piletic M. Adding fast-acting insulin aspart to basal insulin significantly improved glycaemic control in patients with type 2 diabetes: a randomized, 18-week, open-label, phase 3 trial (onset 3). Diabetes Obes Metab. 2017;19:1389-96.

8. Khunti K, Damci T, Husemoen LL, Babu V, Liebl A. Exploring the characteristics of suboptimally controlled patients after 24 weeks of basal insulin treatment: an individualized approach to intensification. Diabetes Res Clin Pract. 2017;123: 209-17.

9. Buse JB, Dailey G, Ahmann AA, et al. Baseline predictors of $\mathrm{A} 1 \mathrm{C}$ reduction in adults using sensor- augmented pump therapy or multiple daily injection therapy: the STAR 3 experience. Diabetes Technol Ther. 2011;13:601-6.

10. Shalitin S, Gil M, Nimri R, de Vries L, Gavan MY, Phillip M. Predictors of glycaemic control in patients with type 1 diabetes commencing continuous subcutaneous insulin infusion therapy. Diabet Med. 2010;27:339-47.

11. Riddle MC, Vlajnic A, Zhou R, Rosenstock J. Baseline HbA1c predicts attainment of $7.0 \% \mathrm{HbA} 1 \mathrm{c}$ target with structured titration of insulin glargine in type 2 diabetes: a patient-level analysis of 12 studies. Diabetes Obes Metab. 2013;15:819-25.

12. Balkau B, Calvi-Gries F, Freemantle N, Vincent M, Pilorget V, Home PD. Predictors of HbA1c over 4 years in people with type 2 diabetes starting insulin therapies: the CREDIT study. Diabetes Res Clin Pract. 2015;108:432-40.

13. Mathieu C, Bode BW, Franek E, et al. Efficacy and safety of fast-acting insulin aspart in comparison with insulin aspart in type 1 diabetes (onset 1): a 52-week, randomized, treat-to-target, phase III trial. Diabetes Obes Metab. 2018;20:1148-55.

14. World Health Organization. Obesity and overweight. 2018. http://www.who.int/mediacentre/ factsheets/fs311/en/. Accessed 25 Sept 2018.

15. Seaquist ER, Anderson J, Childs B, et al. Hypoglycemia and diabetes: a report of a workgroup of the American Diabetes Association and the Endocrine Society. Diabetes Care. 2013;36:1384-95.

16. Gagnon-Auger $\mathrm{M}$, du Souich $\mathrm{P}$, Baillargeon JP, et al. Dose-dependent delay of the hypoglycemic effect of short-acting insulin analogs in obese subjects with type 2 diabetes: a pharmacokinetic and pharmacodynamic study. Diabetes Care. 2010;33:2502-7.

17. Hildebrandt P. Skinfold thickness, local subcutaneous blood flow and insulin absorption in diabetic patients. Acta Physiol Scand Suppl. 1991;603:41-5.

18. European Medicines Agency. Guideline on the investigation of subgroups in 5 confirmatory clinical trials. 2014. https://gmds.de/fileadmin/user upload/Publikationen/Stellungnahmen/20140123_ ema_chmp_draft_guideline.pdf. Accessed 25 Sept 2018. 